1. MBBS, FCPS (Urology) Assistant Professor Urology Khawaja Muhammad Safdar Medical College, Sialkot.

2. MBBS, FCPS (Microbiology) Professor Pathology Khawaja Muhammad Safdar Medical College Sialkot, Pakistan.

3. MBBS, FCPS (Pediatric Medicine) Assistant Professor Paediatric Medicine

The Children Hospital and ICH Lahore.

4. MBBS, FCPS (Urology) Assistant Professor Urology Islam Medical and Dental College Sialkot, Pakistan.

5. MBBS, FCPS (Paediatric Medicine) Assistant Professor Paediatric Gastroenterology

Lahore General Hospital, Lahore.

Correspondence Address:

Dr. Syed Muhammad Hassan Akhtar Department of Urology

Khawaja Muhammad Safdar Medical College, Sialkot.

dsmhau2gmail.com

Article received on: 16/03/2020

Accepted for publication: $27 / 06 / 2020$

\section{Microbes and antibiotic susceptibility patterns of urinary tract infections in toilet-trained Children at a Tertiary Care Hospital of Sialkot, Pakistan.}

\begin{abstract}
Syed Muhammad Hassan Akhtar ${ }^{1}$, Abdul Sattar ${ }^{2}$, Wajiha Rizwan ${ }^{3}$, Naeem Ahmed Cheema ${ }^{4}$, Aftab Anwar ${ }^{5}$

ABSTRACT... Objective: To find out various types of microorganisms causing urinary tract infections and their antibiotic sensitivity patterns among toilet-trained children presenting at a tertiary care hospital of Sialkot District. Study Design: Descriptive study. Setting: Department of Microbiology/Urology, Khawaja Muhammad Safdar Medical College, Sialkot. Period: June to December 2019. Material \& Methods: A total of 176 toilet trained children, aged 7 to 15 years, presenting in outpatient department and having culture positive urinary tract infections were enrolled. Demographic information like age, gender and area of residence along with clinical findings, antibiotic sensitivities and resistance patterns were recorded. Mid-stream urine sample was collected from all toilet-trained children and immediately sent to institutional laboratory for urine analysis and urine culture and sensitivities. Results: Out of a total of 176 children, 95 (54.0\%) were female and $81(46.0 \%)$ male. Overall mean age was noted to be $10.68+2.42$ years while most of the children, 94 (53.4\%) were above 10 years of age. Majority of the patients, $98(55.7 \%)$ belonged to rural areas. Eschericia coli were the most common isolate, found among $140(79.5 \%)$ children. Imipenem (98.9\%), meropenem (98.9\%), piperacillin tazobactam $(97.7 \%)$, fosfomycin $(96.6 \%)$, amikacin $(95.5 \%)$, nitrofurantoin $(84.4 \%)$, gentamycin $(90.9 \%)$ and amoxicillin clavulanate (83\%) were found to have the highest sensitivities. Conclusion: Eschericia coli were the most common bacterial urinary pathogens in toilet-trained children. Amoxicillin clavulanate, Nitrofurantoin and Fosfomycin available in oral form showed good sensitivity of $83 \%, 84.4 \%$, and $96.6 \%$ respectively) to commonly found microorganisms. It was also noted that resistance to commonly used antibiotics in our region is rising.
\end{abstract}

Key words: Microorganisms, Sensitivity, Toilet-trained Children, Urine Culture, Urinary Tract Infection.

Article Citation: Akhtar SMH, Sattar A, Rizwan W, Cheema NA, Anwar A. Microbes and antibiotic susceptibility patterns of urinary tract infections in toilet-trained Children at a Tertiary Care Hospital of Sialkot, Pakistan. Professional Med J 2021; 28(1):22-26. https://doi.org/10.29309/TPMJ/2021.28.01.4657

\section{INTRODUCTION}

Urinary tract infection (UTI) is considered to be one of the most frequent bacterial infections among pediatric population. They are also one of the important causes of hospitalization among children. ${ }^{1,2}$ After upper respiratory traction infections (URTIs), UTIs are described as the most frequent infections. ${ }^{3}$ Variation is observed regarding prevalence of UTI among children. Males are more affected by UTI in the first year of life representing a male to female ratio of around 3 to 5:1. After the first couple of years, female children are more affected than male with a male to female ratio as high as 1:10. Among male children, majority are uncircumcised while female children are commonly affected when they are getting toilet training. ${ }^{4}$ During toddler years, toilet training is seen to lead to volitional holding and bladder stasis, promoting UTIs. ${ }^{5}$ Around $12 \%$ of female children and $4 \%$ male children are expected to have UTIs before the age of 16 years while recurrence of UTIs are also commonly observed. ${ }^{6}$

Urinary tract infection can be asymptomatic or symptomatic. They have been found to contribute to worst outcomes because of sepsis or due to pyelonephritis especially in children of younger age whereas UTI of recurrent nature can impact long term hazards like hypertension or end stage 
kidney disease (ESKD) ${ }^{7,8}$

Escherichia coli, Klebsiella pneumonia and Pseudomonas aeruginosa are some of the most common etiological agents responsible for UTIs among children while other gram negative enteric bacilli and microorganisms that belong to flora of the vagina and peri-urethral region are also found responsible. ${ }^{1,9}$

Selection of the antibiotic in particular individual is dependent upon different factors like age, previous medical history, previous illnesses, antibiotic resistance charts as well as most common etiological agents and their antimicrobial sensitivity testing. ${ }^{10}$ Multidrug resistance (MDR) is described as resistance to 2 or more different structural classes of antimicrobial agents. Rising resistance to many antibiotics is seen throughout the world and is posing a major problem to clinicians. ${ }^{11}$ It is also very important to keep finding the current trends of etiological microorganisms and their antibiotic sensitivity patterns to better treat UTIs. No study has been done in the past at Sialkot, Pakistan so the current study was planned with an aim to find out various types of microorganisms causing UTIs and their antibiotic sensitivity patterns among toilet-trained children (TTC) presenting at a tertiary care hospital of Sialkot District.

\section{MATERIAL \& METHODS}

This was a descriptive observational study done at department of Microbiology/Urology, Khawaja Muhammad Safdar Medical College, Sialkot, from June to December 2019. Approval from Institutional Ethical and Research Committee was taken for this study. Informed consent was taken from the parents or guardians of all the study participants.

A total of 176 toilet trained children (who go to wash room when they feel urge to urinate, not using pampers, have good urinary control and normal continent voiding habit), aged 7 to 15 years, presenting in outpatient department and having culture positive UTI (colony count of $>100,000$ / $\mathrm{cmm}$ of a single organism or $>10,000$ per $\mathrm{cmm}$ in symptomatic children[e.g. fever, incontinence, dysuria, abdominal pain, vomiting).$^{12}$ All children having multiple microorganisms in culture or having history of urological problems (like vesicoureteric reflux, Urinary stones, Post Urethral valves and incontinence), congenital genitourinary anomalies, mentally retarded children (difficult to clean catch their urine sample) or who lost followup, were not enrolled.

Demographic information like age, gender and area of residence along with clinical findings, antibiotic sensitivities and resistance patterns were recorded. Mid-stream urine sample was collected from all TTC and immediately sent to institutional laboratory for urine analysis and urine culture and antibiotic sensitivities.

All the study data was entered and analyzed using SPSS version 22.0. Quantitative variables were represented in terms of mean and standard deviation whereas qualitative variables were highlighted as frequencies and percentages.

\section{RESULTS}

Out of a total of 176 children, 95 (54.0\%) were female and 81 (46.0\%) male. Overall mean age was noted to be $10.68+2.42$ years while most of the children, 94 (53.4\%) were above 10 years of age. Majority of the patients, 98 (55.7\%) belonged to rural areas (Table-I).

\begin{tabular}{|c|c|c|}
\hline \multicolumn{2}{|c|}{ Characteristics } & Number (\%) \\
\hline \multirow{2}{*}{ Gender } & Male & $81(46.0 \%)$ \\
\cline { 2 - 3 } & Female & $95(54.0 \%)$ \\
\hline \multirow{2}{*}{ Age (years) } & $<10$ & $82(46.6 \%)$ \\
\cline { 2 - 3 } & $>10$ & $94(53.4 \%)$ \\
\hline $\begin{array}{c}\text { Area of } \\
\text { Residence }\end{array}$ & Rural & $98(55.7 \%)$ \\
\cline { 2 - 3 } & Urban & $78(44.3 \%)$ \\
\hline
\end{tabular}

Table-I. Characteristics of study participants $(n=176)$

Figure-1 shows the types of microorganisms isolated in the urinary culture. Escherichia coli were the most common isolate, found among 140 $(79.5 \%)$ children while Klebsiella pneumoniae 22 $(12.5 \%)$ and Enterobacter cloacae 8 (4.5\%) were the other most common isolates.

As most of the microorganisms were gram 
negative rods 174/176 (98.9\%), so only sensitivity pattern of gram negative bacteria are shown in Figure number 3 which shows imipenem (98.9\%), meropenem (98.9\%), piperacillin tazobactam (97.7\%), fosfomycin (96.6\%), amikacin (95.5\%), nitrofurantoin (84.4\%), gentamycin (90.9\%) and amoxicillin clavulanate (83\%) were found to have the highest sensitivities.

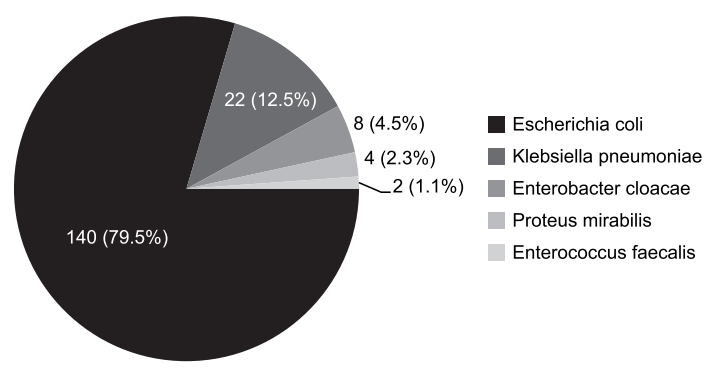

Figure-1. Types of microorganisms isolated in urine culture $(n=176)$

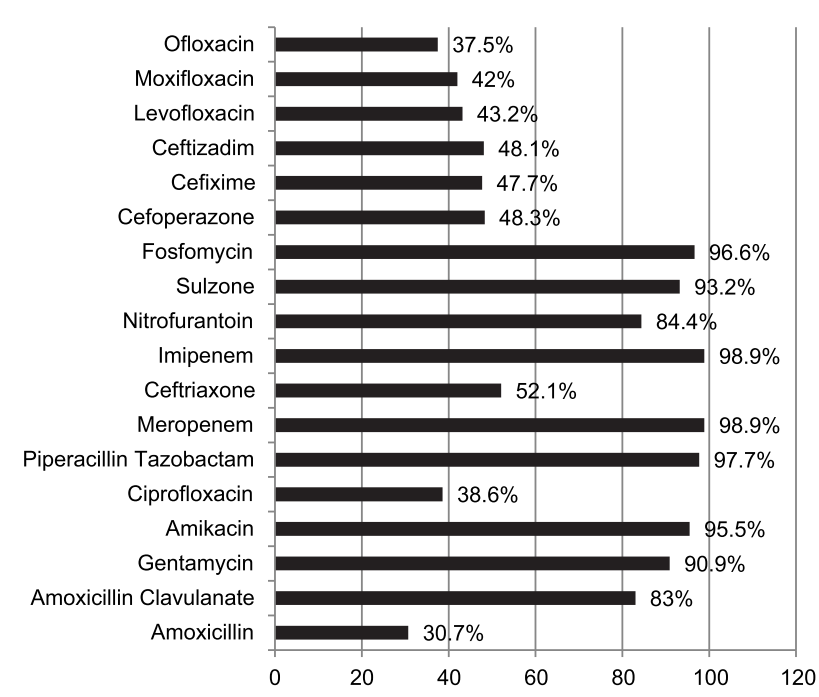

Figure-2. Sensitivity of antibiotics (\%) against gram negative rods in the present study $(n=174)$

\section{DISCUSSION}

Globally, UTIs are estimated to affect around 150 million people annually. Frequent recurrence, pyelonephritis along with the sepsis, kidney injury in younger children as well as frequent use of antimicrobials causing resistance is some of the most serious sequelae of UTIs in pediatric population. ${ }^{13}$

Following infancy, female children are more prone to have UTIs in comparison to male especially due to short urethra size in female making it easy for bacteria to travel up to urinary tract. Finding of the present study were quite consistent to these facts as majority, $54.0 \%$ children in the present study were female. Local and international data also exhibit majority of the children affected with UTIs to be females. ${ }^{14,15,16,17}$

Researchers from around the world have found Escherichia coli to be the most commonly found isolate causing UTIs. ${ }^{18,19}$ In the present work, Escherichia coli was found among $79.5 \%$ isolates. A local study from Islamabad ${ }^{12}$ among children aged 3 months to 12 years noted $E$. coli to be the most frequent isolate found (57.3\%). Another local study from Swabi found that $67.0 \%$ culture positive samples had stains of Escherichia coli whereas another one found the presence of Escherichia coli to be $76.3 \%$ in cases of UTIs. Gram negative bacteria, mainly Escherichia coli and Klebsiella pneumoniae are the predominant causative agents among cases of UTIs. ${ }^{14,20}$

Sensitivity finding regarding various antibiotics used in our region noted that isolated microorganisms showed low-to-poor sensitivity to the commonly used antibiotic options like ciprofloxacin, ceftizadim, cefoperazone and ceftriaxone. Among these findings, resistance among some of the most commonly used fluoroquinolones for the treatment of UTIs in children like ciprofloxacin showed poor sensitivity $(38.6 \%)$ in the present study. Ciprofloxacin is commonly adopted as choice of treatment of UTIs but current findings show that its effectiveness is not up to the accepted standards. It is also important to keep in mind that fluoroquinolones are thought to have advantages over other commonly considered antibiotic like amoxicillin clavulanate with regards to its pharmacokinetic characteristics. Our findings were quite different to another local study ${ }^{12}$ where flouroquinolones were noted to have $100 \%$ sensitivity against common causative agents of UTls among children. The difference could be because of changes in trends of antibiotic resistance in this region. Flouroquinolones have always been considered a very good option for treating UTIs but this study shows that their sensitivity is not 
as good as it is thought to be in our region. On the other hand, amoxicillin clavulanate in the present study showed a sensitivity of $83 \%$ mainly among Escherichia coli isolates (found among $97.8 \%$ of the isolates in the present study) which shows the effectiveness of this affordable and commonly available drug in our region of Sialkot. Other local researchers have also found that fluoroquinolones-resistant to most common uropathogens is increasing noting that to be $59 \%$ while extended spectrum $\beta$-lactamase producing fluoroquinolone-resistant uropathogenic strains have significantly been increased in the AsianPacific region and India. ${ }^{21,22}$

Ceftriaxone is another commonly adopted antibiotic used in UTIs. The current study found sensitivity of ceftriaxone as $59.1 \%$. Previous data from Iraq found commonly found isolates among children having UTIs to be resistant against ceftriaxone $75 \%$ of the cases while Niranjan $V$ et al from India, Al-Mijalli SH from Saudi Arabia noted that to be $71.4 \%$ and $98.9 \%$ respectively. ${ }^{23,24,25}$

We noted good sensitivity of imipenem (98.9\%), meropenem (98.9\%), piperacillin tazobactam $(97.7 \%)$, fosfomycin (96.6\%), amikacin (95.5\%), nitrofurantoin (84.4\%), and gentamycin (90.9\%). These findings are very similar to other local and regional data and demonstrate the effectiveness of these antibiotics as these are less commonly used in our community. ${ }^{12,26,27}$

This was the first study analyzing various types of microorganisms causing UTIs and their antibiotic sensitivity patterns among toilet-trained children (TTC) at a tertiary care hospital of Sialkot District, Pakistan. The results of this study should help clinicians getting an idea of the commonly involved microbes when treating children of our area having UTIs and also while prescribing, choose the good orally available antibiotics when considering empirical therapy in selective cases. One of the limitations of this study was that we could not gather treatment outcome data of studied children which would have further provided us some insight about the treatment responses as well.

\section{CONCLUSION}

Escherichia coli were the most common bacterial urinary pathogens in toilet-trained children. Common available antibiotics in oral form safe in children (amoxicillin clavulanate, Nitrofurantoin, fosfomycin) showed good sensitivity to most commonly found cultured microorganisms. Resistance to commonly used antibiotics (ceftriaxone, Quinolones) in our region is rising. Copyright $@ 27$ June, 2020.

\section{REFERENCES}

1. Koçak $M$, Büyükkaragöz $B$, ÇelebiTayfur $A$, Çaltik $A$, Köksoy AY, Çizmeci Z, et al. Causative pathogens and antibiotic resistance in children hospitalized for urinary tract infection. Pediatrlnt 2016; 58:467-71.

2. Amber $M$, Shoaib $M$, Rehman $A$, Zafar MM, Ain $Q$, Naseer F, et al. Comparative study of causative agents of UTI among indoor, outdoor, children and adult patients of Pakistani Population. Bull. Env. Pharmacol. Life Sci 2016; 5(8):34-41.

3. Farajnia S, Alikhani MY, Ghotaslou R, Naghili B, Nakhlband $A$. Causative agents and antimicrobial susceptibilities of urinary tract infections in the northwest of Iran. Int J Infect Dis 2009; 13:140-4.

4. Elder JS. Urinary tract infections. In: Klegman RM, Stanton BF, St Geme JW, Schor NF, Behrman RE, eds. Nelson Textbook of pediatrics. 20th ed. Philadelphia: Elsevier, 2016; pp 2556-61.

5. Tullus K. Fifteen-minute consultation: Why and how do children get urinary tract infections? Arch Dis Child Educ Pract Ed. 2019; 104(5):244-7.

6. Lacromb J. Urinary tract infection in children. BMJ ClinEvid. 2010; 2010:0306.

7. Al-Harthi AA, Al-Fifi SH. Antibiotic resistance pattern and empirical therapy for urinary tract infections in children. Saudi Med J. 2008; 29:854-58.

8. Elder JS. Urinary tract infections. In: Klegman RM, Stanton BF, St Geme JW, Schor NF, Behrman RE, eds. Nelson Textbook of pediatrics. 20th ed. Philadelphia: Elsevier, 2016; pp 2556-61.

9. Badhan $R$, Singh $D V$, Badhan $L$ R. Evaluation of bacteriological profile and antibiotic sensitivity patterns in children with urinary tract infection. Ind $\mathrm{J}$ Urology; 2016; 32(1):50-6.

10. Brad G, Sabu I, Marcovici T, Mari I, Descu C, Belei O, et al. Antibiotic resistance in urinary tract infections in children. Jurnalul Pediatrului 2010; 13:51-2. 
11. Srinivasan S, Madhusudhan NS. Prevalence of multidrug resistant pathogens in children with urinary tract infection: A retrospective analysis. Int J Med Res Health Sci 2014; 3:954-8.

12. Hussain M, Ahmad B, Bhatti N, Husain S. Bacteriological spectrum and sensitivity pattern in culture proven urinary tract infection in children. JRMC 2017; $21(3): 290-2$.

13. Foxman B. Urinary tract infection syndromes: Occurrence, recurrence, bacteriology, risk factors, and disease burden. Infect Dis Clin North Am 2014; 28:1-13.

14. Jamil J, Haroon M, Sultan A, Khan MA, Gul N, Kalsoom. Prevalence, antibiotic sensitivity and phenotypic screening of ESBL/MBL producer $E$. coli strains isolated from urine; District Swabi, KP, Pakistan. JPMA 2018; 68(11):1704-7.

15. Asinobi AO, Fatunde OJ, Brown BJ, Osinusi K, Fasina NA. Urinary tract infection in febrile children with sickle cell anaemia in Ibadan, Nigeria. Ann. Trop. Paediatr. 2003; 23(2):129-134.

16. Saeed $\mathrm{CH}, \mathrm{AL}-$ Otraqchi KIB, Mansoor IY. Prevalence of urinary tract infections and antibiotics susceptibility pattern among infants and young children in Erbil city. Zanco J Med Sci 2015; 19:915-22.

17. Abuhandan M, Güzel B, Oymak Y, Çiftçi H. Antibiotic sensitivity and resistance in children with urinary tract infection in Sanliurfa. Turk J Urol2013; 39:106-10.

18. Mirsoleymani SR, Salimi M, ShareghiBrojeni M, Ranjbar M, Mehtarpoor M. Bacterial pathogens and antimicrobial resistance patterns in pediatric urinary tract infections: A fouryear surveillance study (20092012). Int J Pediatr. 2014; 126142.
19. Singh SD, Madhup SK. Clinical profile and antibiotics sensitivity in childhood urinary tract infection at Dhulikhel Hospital. Kathmandu Univ Med J (KUMJ). 2013; 11:319-24.

20. Ahmed I, Sajed M, Sultan A, Murtaza I, Yousaf S, Maqsood B, et al. The erratic antibiotic susceptibility patterns of bacterial pathogens causing urinary tract infections. Excli J. 2015; 916-25.

21. Ali I, Rafaque Z, Ahmed S, Malik S, Dasti JI. Prevalence of multi-drug resistant uropathogenic Escherichia coli in Potohar region of Pakistan. Asian Pacific Journal of Tropical Biomedicine 2016; 6(1):60-6.

22. Dalhoff A. Global fluoroquinolone resistance epidemiology and implications for clinical use. Interdiscip Perspect Infect Dis 2012:976273.

23. Saeed $\mathrm{CH}, \mathrm{AL}-$ Otraqchi KIB, Mansoor IY. Prevalence of urinary tract infections and antibiotics susceptibility pattern among infants and young children in Erbil city. Zanco J Med Sci 2015; 19:915-22.

24. Niranjan V, Malini A. Antimicrobial resistance pattern in Escherichia coli causing urinary tract infection among inpatients. Indian J Med Res 2014; 139:945-8.

25. Al-Mijalli SHS. Bacterial uropathogens in urinary tract infection and antibiotic susceptibility pattern in Riyadh Hospital, Saudi Arabia. Cell Mol Med 2017; 3:1-6.

26. MajumderMI. Bacteriology and antibiotics sensitivity patterns of UTI in tertiary hospital in Bangladesh. Mymensingh Med. J2014; 23(1):99-104.

27. Raheem RS, Hussein MA, AI-Din NI. Causative organism of urinary tract infection and drug resistance in children at child's Central Teaching Hospital in Baghdad City. JPMA 2019; 69(Suppl.3) S-59.

\begin{tabular}{|c|l|l|l|}
\hline \multicolumn{3}{|c|}{ AUTHORSHIP AND CONTRIBUTION DECLARATION } \\
\hline Sr. \# & \multicolumn{1}{|c|}{ Author(s) Full Name } & \multicolumn{1}{|c|}{ Contribution to the paper } & Author(s) Signature \\
\hline 1 & Syed M. Hassan Akhtar & $\begin{array}{l}\text { Data Collection, Drafting } \\
\text { Supervision. } \\
\text { Methodology, Data analysis. }\end{array}$ \\
\hline 2 & Abdul Sattar & $\begin{array}{l}\text { Study Concept, Data } \\
\text { interpretation. } \\
\text { Literature review, Discussion. }\end{array}$ \\
\hline 4 & Wajiha Rizwan & $\begin{array}{l}\text { Naeem Ahmed Cheema } \\
\text { Proof reading, Literature } \\
\text { review. }\end{array}$ \\
\hline
\end{tabular}

